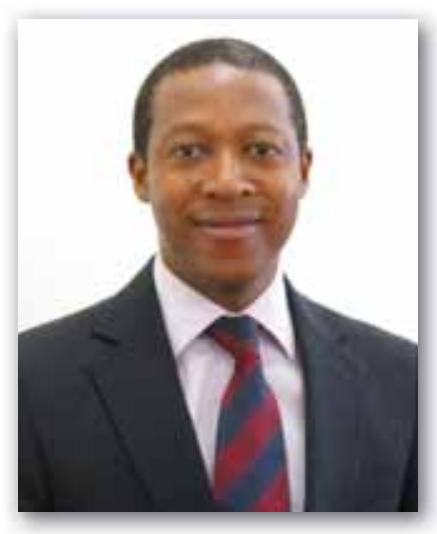

\author{
Editor, Ntobeko A.B. Ntusi \\ Professor of Medicine; Chair and Head, Department of Medicine, \\ University of Cape Town and Groote Schuur Hospital, \\ Observatory, South Africa
}

\title{
Racism in medicine, science and in medical publishing
}

Black Lives Matter is an activist movement which began as a hashtag (\#BlackLivesMatter) after George Zimmerman was acquitted in the shooting death of Trayvon Martin, an unarmed African American teenager killed in Florida in July 2013. Black Lives Matter has evolved into a global movement focused on ending systemic bias and structural inequality, and more recently focused on racism in medicine. As a journal that disseminates medical findings and information, we pledge to play our part in eliminating all forms of racism in science, medicine and medical publishing. As academics and scientists, we need to rise to resist injustice and to rebuild a future that is rooted in human rights and true equality. We must cherish the principles of equality, diversity, globalism, empathy and restorative justice, which have been the foundations of the Black Lives Matter Movement.

Of course, we cannot talk about equality and social justice in South Africa without reflecting on the history of our country. The legacy of apartheid, legalised segregation and enforced separate development of the different racial groups, is evident in all aspects of our society today. It created a social system which severely disadvantaged the majority of the population, simply because of their skin colour.

From 1948 to the early 1990s, the country's majority black population lived under white minority rule of systemic discrimination and racism. The government of the day instituted policies of white supremacy, which empowered white South Africans while disenfranchising black South Africans. Until the early 1990s, when South Africa became an inclusive democracy, black African workers were forced to live in townships - informal peri-urban residential areas without proper planning or services. Systemic segregation dated back to the colonial era: in the late 19th and early 20th centuries, the British colonial government resettled racial groups under the pretence of responding to disease epidemics in overcrowded neighbourhoods: the South-West townships (Soweto) were settled by blacks who were relocated after an outbreak of bubonic plague in central Johannesburg. Early separation was formalised and reinforced by colonial laws such as the Natives Land Act of 1913, which reserved nearly $90 \%$ of the land in South Africa for a tiny minority white population. In the following decades, during which South Africa became an independent republic, a series of pass laws comprehensively restricted the rights of the black population. Through the Group Areas Act of 1950, cities were designated "for whites only", and townships became, in effect, the mechanism for housing the black labour force. 
Today, in South Africa, black communities still have limited opportunities to access health, education, jobs, housing and security, and the right to live a happy, healthy and fulfilling life. As the Editor of the South African Heart Journal, I believe that the responsibility for fixing these disparities lies with all of us. In acknowledging our role as part of a system that enables the perpetration of inequality, I hope to leverage our position as a trusted source of information in the translational and clinical cardiovascular sciences to actively pursue and amplify important discussions about racial disparities in the context of health and cardiovascular medicine. I pledge to increase the representation of black authors and of other under-represented subsets of our readership in our pages, whether through commissioned content, by increasing the reach of our outreach activities, by the diversification of our referee pool, or by identifying and fostering research that addresses the current racial disparities in science and medicine. I also pledge to be vigilant of research that may perpetuate and enable racism.

In the pages of journals, there have been many records of scientific abuses that have been published under the guise of biomedical scientific advancement. For instance, in the Tuskegee study, black men with syphilis were not informed of their status and did not receive treatment. Similarly, one of the most widely used experimental cell lines in oncology, HeLa cells, were originally taken from Henrietta Lacks' body, a black woman, without her consent. Sims' vaginal speculum was developed through horrific surgeries performed on enslaved black women without anaesthesia. Closer to home, for over a century, the medical professional identity and composition was highly racialised, with many stereotypes based on assumptions about the different categories of race groups. For instance, in the 1800s and 1900s, doctors treated black and white patients with mental health problems differently, and in the 1890s, began to advance theoretical arguments to justify this practice. The case of leprosy in the 1900s is another example in public health, where black patients were sent to Robben Island for treatment, while white South African patients were treated from home, leading to the racist stereotyping of the leper as black. A recent publication on black registrars in training at Western Cape academic hospitals highlighted experiences of racism during work hours, the psychological effects of tokenism, institutional racism and an organisational culture characterised by race and gender bias.

Such biases continue to affect medical research and clinical practice today. Blacks are still underrepresented in clinical trials. Structural inequality and systemic biases disproportionately affect the health of black people, and this has recently been brought into stark focus by the COVID-19 pandemic, during which black people are dying disproportionately relative to other groups.

In conclusion, systemic bias and structural inequality, including within medicine, are one of the defining public-health challenges of our time. Actively combating these must be a priority for all segments of our society. And I ask you, our readers, to hold us accountable for our progress. The time to act with conviction is now. 